\title{
Trichophyton sp. Suşundan Keratinaz Üretimi, Saflaştırılması ve Kısmi Karakterizasyonu
}

\section{Donay PARLAK ${ }^{1}$, Hüseyin TANIŞ2 ${ }^{2}$, Ashabil AYGAN ${ }^{3}$}

Kahramanmaraş Sütçüimam Üniversitesi Fen-Edebiyat Fakültesi Biyoloji Bölümü Avşar kampüsü Onikişubat-K..Maraş ${ }^{1}$ https://orcid.org/0000-0002-8940-5842, ${ }^{2}$ https://orcid.org/0000-0002-2012-7864, ${ }^{3}$ https://orcid.org/0000-0003-4936-9872

$\bowtie$ : huseyintanis23@hotmail.com

\section{ÖZET}

Keratinaz aktivitesi gösteren Trichophyton sp. Tr-9 suşu keratin tozufeather meal içeren minimal besiyerinde büyütürek enzim üretimi gerçekleştirilmiştir. Süpernatanttan Amonyum sülfat çöktürme sonrası, Sephadeks G-100 ve DEAE Sepharose kolon kromatografi uygulamaları ile enzim saflaştırılması yapılmıştır. Maksimum keratinolitik aktivite $\mathrm{pH} 7.5$ ve $37^{\circ} \mathrm{C}$ 'de gözlenmiştir. Enzim pH 5.58.0 ve $20^{\circ} \mathrm{C}-40^{\circ} \mathrm{C}$ sicaklık aralıklarında stabilite gösterirken, enziminin moleküler ağırlı̆̆ SDS page ve zimogram analizlerinde yaklaşık 34 kDa olarak hesaplandı. $\mathrm{CaCI}_{2}(5 \mathrm{mM})$ keratinaz aktivitesini (\%148) stimüle edici etki gösterdi. Diğer taraftan EDTA $(5 \mathrm{mM})$ ve SDS (\%1) sirasıyla \%49, \% 49 etki göstererek kısmen inhibe etti, PMSF (1mM ve $5 \mathrm{mM}$ ) ile tam inaktivasyon elde edildi. Sonuç olarak, enzimin fiziko-kimyasal özellikleri birçok endüstriyel ve biyoteknolojik uygulamalarda kullanışlı olabileceğini göstermiştir.
Araştırma Makalesi

$\begin{array}{ll}\text { Makale Tarihçesi } \\ \text { Geliş Tarihi } & : 22.01 .2020 \\ \text { Kabul Tarihi } & : 13.03 .2020\end{array}$

Anahtar Kelimeler

Trichophyton sp.,

Keratinaz

Saflaştırma

Karakterizasyon

\section{Isolation and Partial Characterization of Keratinase from Trichophyton sp.}

\section{ABSTRACT}

Keratinase enzyme production was accomplished from Trichophyton sp. Tr-9 in minmal medium containing feather meal. Enzyme was purified with Ammonium sulfate, Sephadeks G-100 and DEAE Sepharose column. Maxiumum keratinolitik activity was obtained at $\mathrm{pH} 7.5$ and $37^{\circ} \mathrm{C}$. Enzyme was higly stabil between $\mathrm{pH}$ 5.5-7.5 and 20$40^{\circ} \mathrm{C}$. With the SDS-Page analysis of the enzyme, molecular weight of the enzyme was calculated as $34 \mathrm{kDa}$. $\mathrm{CaCI}_{2}(5 \mathrm{mM})$ had a stimultory effect $(148 \%)$ on enzyme. On the other hand, EDTA $(5 \mathrm{mM})$ and SDS (\%1) inhibited enzyme acitivity up to $49 \%$ and $49 \%$, respectively. PMSF (1-5mM) has strongly inhibited enzyme. As a result, physicochemical properties of the enzymeshowed that Trichophyton sp. Tr-9 could be useful in various industrial and biotechnological applications.

\section{Research Article}

$\begin{array}{ll}\text { Article History } & \\ \text { Received } & : 22.01 .2020 \\ \text { Accepted } & : 13.03 .2020\end{array}$

\author{
Keywords \\ Trichophyton sp., \\ Keratinase \\ Purification \\ Characterization
}

To Cite : Parlak D, Tanış H, Aygan A 2020. Trichophyton sp. Suşundan Keratinaz Üretimi, Saflaştırışması ve Kısmi Karakterizasyonu. KSÜ Tarım ve Doğa Derg 23 (5): 1135-1143. DOI: 10.18016/ksutarimdoga.vi.678756.

\section{GİİŞ}

Biyokimyasal olayların gerçekleşmesinde önemli role sahip olan enzimler özelleşmiş fonksiyonlara sahip katalizörledir. Enzimler çeşitli kaynaklardan elde edilebilir. Endüstriyel anlamda kullanım potansiyeli yüksek olan enzimler daha çok mikrobiyal kaynaklı olanlardır (Gupta ve ark., 2003).Mikrobiyal enzimlerin endüstriyel alanda tercih edilmelerinin başlıca sebepleri istenmeyen yan ürün oluşturmamaları, katalitik aktivitelerinin yüksek olması, oldukça stabil ve ucuz olmaları, yüksek oranda ve saflıkta elde edilebilmeleridir (Horikoshi, 1999). Mikroorganizmalar tarafindan üretilen enzimlerin birçoğu hücre içinde aktif iken bazıları hücre dışına salgılanıp hücre dışında aktif olabilir, böyle enzimlere ekstraselüler enzimler denir. Ekstraselüler enzimler, mikroorganizmaların ihtiyacı olan besin kaynaklarını hidrolizleyerek kullanabilmelerini sağlar. Biyoteknolojik alanda kullanılan enzimlerin yaklaşık \% 75'ini hidrolitik enzimler oluşturmaktadır (Bhat, 2000).Bunlardan proteazlar (E.C. 3.4.21/24 / 99) doğada hemen hemen her alanda bulunabilen yaygın enzimlerdir.Proteolitik enzimler, protein substratlarının hidrolizini içeren biyoteknolojik uygulamalar için endüstride yaygın kullanılır. Piyasadaki proteazların önemli bir bölümü ise mikrobiyal keratinazlardır (Rao ve ark., 1998).

Keratin, doğada bulunan en önemli yapısal proteinlerden biridir ve yaygın olarak omurgalıların dış yüzeylerinde bulunur. Kollajenden sonra hayvanlarda karşlaşılan en önemli biyopolimerdir. Kıl ve tüy atıkları tarımsal sanayide yan ürün olarak 
üretilmektedir. $\mathrm{Bu}$ tür atıkların birikimi çevresel problemlere sebep olabilmektedir. Keratinler, yapısındaki sülfür içeriğine göre ise sert ve yumuşak keratinler olarak gruplandırılabilir. Yumuşak keratinler cilt ve nasırda bulunup daha az disülfit bağı içerir ve daha esnektir, yumuşak keratinlerin aksine sert keratinler ise saç, tüy, boynuz ve tırnak gibi uzantıları oluştur ve yüksek oranda disülfit bağı içerir (Voet ve Voet, 2008;Mckittrick ve ark., 2012). Keratince zengin atıkların bozulmaları zordur çünkü polipeptidler yoğun bir şekilde paketlenmiş olan çok güçlü hidrojen bağlarının varlığıyla daha stabil olmuştur. Ayrıca hidrofobik etkileşimler, protein zincirlerinin çarpraz bağlanmaları ve birçok disülfit bağı içermeleri nedeniyle oluşan yüksek mekanik stabilite, keratinlerin yaygin birçok proteazca parçalanmalarına direnç sağlar (Kreplak ve ark., 2004). Dirençlerine rağmen keratinler çok sayıda bakteri, fungus ve aktinomiset tarafindan salgilanan keratinolitik protezlar tarafindan etkili bir şekilde parçalanabilir (Onifade ve ark., 1998). Mikrobiyal keratinazlar genellikle alkalin ve nötr proteazlardır ve optimum $\mathrm{pH}$ aralıkları 7.5- 9.0 arasında değişkenlik gösterir fakat bu aralığın dışında yer alan enzimlerde vardır. Extrem alkolofilik $\mathrm{pH}$ aralığında aktif olanların yanı sıra nadiren asidik $\mathrm{pH}$ 'da aktif keratinazlar da vardır (Takami ve ark., 1999). Çoğu keratinaz üreten mikroorganizma keratinaz üretimini büyük bir ölçüde bazal bir ortam içerisinde gerçekleştirir. Karbon ve azot kaynağı olarak ise keratini kullanmaktadır (Gousterova ve ark., 2005). Keratinaz üreticisi çeşitli mikroorganizmalar bir çok araştırmacı tarafından belirlenmiş ve enzim karakterizasyonları gerçekleştirilmiştir (Gupta ve ark, 1999; Vidyasagar ve ark., 2006; Bernal ve ark. 2006 Riffel ve ark, 2007). Ancak, dermatofitik fungusların keratinolitik potansiyelleri son zamanlarda dikkat çekmektedir, özellikle Trichophyton ve Mikrosporum gibi cinsler bu proteolitik etkileri nedeniyle ilgi uyandırmaktadır (Anbu ve ark, 2008). Bu özel grup patojenik fungusların keratin substratını en iyi parçalayan mikroorganizmalar arasında yer alması, keratin atıklarının biodegradasyonunda da önemli rol oynaması anlamına gelmektedir (Muhsin ve ark., 2002).

Günümüzde keratinaz enzimleri yem, gübre, deterjan, deri,ve ilaç endüstrileri gibi bir çok alanda yaygin olarak kullanılmaktadır. Örneğin keratinaz enzimler ile kısmen parçalanmıs tüyler hayvan yemi katkısı olarak kullanılırken, deri endüstrisinde kıl giderim işlemlerinde yaygın olarak kullanılmaktadır (Fakhfakh-Zouari ve ark., 2010). Son zamanlarda yapılan araştırmalar bakteriyel keratinazların deli dana ve scrapie hastalık etkeni olan prion proteinlerinin degradasyonunda da etkili olduğu tespit edilmiştir (Langeveld ve ark., 2003).

Bu çalışmada, keratinaz üreteicisi Trichophyton sp.Tr-
9 izolatının enzim üretimi potansiyeli araştırılmış ve üretilen enzimin kısmi saflaştırılması ve bazı biyokimyasal özellikleri belirlenerek karakterizasyonu amaçlanmıştır.

\section{MATERYAL ve METOD}

\section{Mikroorganizma Örnekleri}

Enzim üretimi gerçekleştiren izolatların belirlenmesi ve enzim üretimi potansiyellerinin değerlendirilmesi için KSU FEF Mikoloji laboratuvarı ve Tıp Fakültesi Mikrobiyoloji laboratuvarı kültür kolleksiyonlarından temin edilen Trichophyton sp. izolatları kullanılmıştır.

\section{Mikroorganizma Kültürü ve Keratinolitik} Aktivitelerinin Belirlenmesi

Mantar kültürü ve canlandırma-büyütme işlemleri Sabouraud dextrose agar (Merck 1.07315) da gerçekleştirilmiştir. Daha sonra suşların proteolitik aktivitelerini varlığını belirlemek amacı ile modifiye Skim-milk agar (Mohamedin, 1999) üzerine ekim yapılarak hidrolitik zonlar belirlenmiştir. Proteaz aktivitesi gösteren suşlar daha sonra keratin tozu (feather meal $0.5 \mathrm{~g} / \mathrm{L}$ ) içeren minimal besiyerinde $\left(\mathrm{MgSO}_{4} 7 \mathrm{H}_{2} \mathrm{O}^{-0} 0.5, \mathrm{KCl}-0.5, \mathrm{KH}_{2} \mathrm{PO}_{4}-0.46, \mathrm{~K}_{2} \mathrm{HPO}_{4}-1\right.$, Agar agar -15 g/L) 15 gün üretilerek (Marcondes ve ark., 2008) keratinolitik aktivite belirlenmesi gerçekleştirilmiştir.

\section{Enzim üretimi}

Keratinaz enzim üretimi için, sıvı Sabouraud dextrose da aktifleştirilmiş Trichophyton sp TR-9 suşundan 0.1 $\mathrm{mL}$ alınarak $0.5 \mathrm{~g} / \mathrm{L}$ keratin tozu içeren minimal besiyerine $\left(\mathrm{MgSO}_{4} .7 \mathrm{H}_{2} \mathrm{O}^{-}-0.5, \mathrm{KCl}-0.5, \mathrm{KH}_{2} \mathrm{PO}_{4}^{-} 0.46\right.$, $\mathrm{K}_{2} \mathrm{HPO}_{4^{-}}$1, $^{2}$ (Marcondes ve ark., 2008) aşlanarak $30^{\circ} \mathrm{C}$ 'de $150 \mathrm{rpm}$ çalkalama hızına ayarlanmış inkübatörde 10 gün inkübasyona bırakılmıştır. İnkübasyon süresi sonunda kültür içeriği ve fungus hiflerifiltre kâğıdından (Whatman No 5) süzülerek filtrat toplanmıştır (Tanış ve Cihangir, 2009). Filtrat, daha sonraki çalışmalarda ham enzim kaynağı olarak kullanılmıştır.

\section{Enzimin Saflaştırılması}

Tr-9 keratinaz enzim saflaştırılması, filtrat üzerine $+4^{\circ} \mathrm{C}$ 'de amonyum sülfat tuzu eklenerek ile fraksiyonel presipitasyon şeklinde gerçekleştirilmiştir. Presipitasyona bırakılan enzim örnekleri \% 40, \% 50, $\% 60, \% 70, \% 80$ ve \% 90'llk amonyum sülfat konsantrasyonları ile fraksiyonel olarak ayrı ayrı toplanmıştır. Presipitatların toplama işlemi 4020 gve $+4^{\circ} \mathrm{C}$ ' de $30 \mathrm{dk}$ santrifüjde (Hettich Mikro 22R) gerçekleştirilmiştir. Enzim örnekleri daha sonra $\mathrm{pH}$ 7.5' daki $100 \mathrm{mM}$ fosfat (Burhan ve ark., 2003) tamponunda çözdürülerek aynı tampona karşı bir gece diyaliz edilmiştir. Diyaliz edilen örnekler $\mathrm{pH}$ 7.5' daki $100 \mathrm{mM}$ fosfat tamponu ile dengelenmiş sephadeks G- 
100 (Sigma) kolon kromatografisinden $(1 \times 30 \mathrm{~cm}) 14$ $\mathrm{mL} / \mathrm{sa}$ hızda aynı tampon ile elue edilmiştir. Daha sonra bir kısım eluat DEAE-Sepharose CL-6B (Sigma) kolondan $(1 \times 15 \mathrm{~cm})$ geçirilerek ekstra saflaştırmaya tabii tutulmuştur. Kolona enzim yüklendikten sonra $20 \mathrm{~mL} / \mathrm{sa}$ hizda $40 \mathrm{~mL}$ daki fosfat tamponu (pH7.5) geçirilmiştir. Kolonda tutulmuş enzim daha sonra 0.1 den $2 \mathrm{M}$ konsantrasyonda değişen $\mathrm{NaCl}$ çözeltisi ile toplanmıştır.

\section{Moleküler Ağırlık ve Zymogram Analizleri}

Tr-9 Keratinaz enziminin moleküler ağırlığı \%10'luk SDS-PAGE (Laemmli, 1970) ile belirlenmiştir. Markör olarak, SDS6H2 (SIGMA) protein karışımı (Domuz miyozini -200 kDa, E. coli B-Galaktosidazı -116 kDa, tavşan kası fosforilazı b -97 kDa, sığır albümini- 66 $\mathrm{kDa}$, ovalbumin- $45 \mathrm{kDa}$ ve sığır eritrosit karbonik anhidrazı- $29 \mathrm{kDa}$ ) kullanılmıştır. Elektroforez sonrası protein bantları gümüş boyama ile görünür hale getirilmiştir (Rabilloud, 1999). Enzimin zimogram analizi için ise \% 10' luk ayırıcı jele içerisine amonyum persülfat eklenmeden hemen önce \% 0.1' lik kazein eklenerek proteolitik aktivite tayini ile gerçekleştirilmiştir(Ferrero ve ark.,1996).

\section{Enzim Aktivite İşlemleri}

Mümkün olduğu kadar küçük parçalara bölünmüş keratin azure (Sigma Chemical, St, Louis, MO, USA) kullanılarak enzim aktivitesi kolorimetrik olarak tayin edilmiştir (Suntornsuk ve Suntornsuk, 2003). Bunun için keratin azure $4 \mathrm{mg} / \mathrm{mL}$ konsantrasyonda $0.01 \mathrm{M}$ sodyum-fosfat $(\mathrm{pH}$ 7.5) tamponunda karıştırılmıştır (Esawy, 2007). Eşit miktardaki enzim ve subsratın $37^{\circ} \mathrm{C}$ 'de $150 \mathrm{rpm}$ 'de 1saat inkübasyonu gerçekleştirilmiştir. İnkübasyondan sonra $4000 \mathrm{gve}$, $+4^{\circ} \mathrm{C}$ 'de, $15 \mathrm{dk}$ santrifüj edilerek keratin azure uzaklaştırılmıştır. Daha sonra karışımdan $1 \mathrm{~mL}$ alınarak spektrofotometrede (Perkin Elmer Lambda EZ 150) 595 nm'de okunup serbest kalan azoboyası ölçülmüştür. Bir ünite (U) keratinaz verilen koşullarda, 1 saatte 595 nm'de 0.1 absorbans artışına neden olan enzim miktarı olarak tanımlanmıştır. Tüm denemeler 3'lü tekrarlar şeklinde gerçekleştirilmiştir.

\section{Sicaklık ve pH'nın Enzim Aktiviteleri ve Stabiliteleri Üzerine Etkisi}

Enzimin optimum $\mathrm{pH}$ ve optimum sicaklık değerleri $\mathrm{pH} \quad 4.0^{-9} 9.0$ ve $20^{-45}{ }^{\circ} \mathrm{C}$ sicaklıklar arasinda test edilerek belirlenmiştir. Optimum $\mathrm{pH}$ belirlemesi için Sitrat tamponu ( $\mathrm{pH} 4.0^{-5.6}$ ), Sodyum fosfat ( $\mathrm{pH}$ 6.07.5) ve Tris (pH8.0-9.0) tampon sistemlerinden yararlanılmıştır. Tr-9 enziminin sıcaklık stabilitesi için 20-70 ${ }^{\circ} \mathrm{C}$ arasında optimum $\mathrm{pH}$ 'da $30 \mathrm{dk}$ ön inkübasyona maruz bırakıldıktan sonra belirlenmiştir. Diğer taraftan $\mathrm{pH}$ stabilite denemeleri ise optimum sicaklıkta pH 4.0-9.0 arasında farklı pH'larda $30 \mathrm{dk}$ ön inkübasyon yapılarak gerçekleştirilmiştir.

\section{Keratinaz Aktivitesi Üzerine Bazı Kimyasalların} Etkisi

Farklı kimyasalların Tr-9 üzerine etkisi farklı konsantrasyonlarda (1-5 mM) optimum sicaklık ve pH'daki ön inkübasyonu ile belirlenmiştir. Bunun için $\mathrm{FeCl}_{3}$, 1,10-Phenanthrolin monohidrat, EDTA (Ethylene diamine tetraacetic acid), PMSF (Fenilmetilsülfonil florit), $\mathrm{ZnCl}_{2}$, Üre, $\mathrm{CaCl}_{2}, \% 1$ 'lik Triton-X 114 ile \%1'lik SDS kullanılmıştır.

\section{Enzimin tüy parçalama yeteneğinin araştırılması}

Kapaklı tüpler içerisine eklenmiş tavuk tüyleri üzerine $100 \mathrm{mM} \mathrm{pH} 7.5$ fosfat tamponu ilave edilerek otoklavda $15 \mathrm{dk}$ sterilizasyon gerçekleştirildi. Oda sıcaklığına ulaşan tüplere $1 \mathrm{~mL}$ filtrat/enzim ilave edilerek $150 \mathrm{rpm}$ ve $37^{\circ} \mathrm{C}$ de inkübe edilerek enzimin tüy parçalama yeteneği gözlemlenmiştir (Korkmaz ve ark., 2003).

\section{BULGULAR ve TARTIŞMA}

Toplam 15 Trichophyton sp.suşuproteolitik aktivite tayini için test edilmiş ve en yüksek proteolitik aktivite gösteren suşlar arasında keratinolitik aktivite gösterenlerden en geniş hidrolitik zon oluşturan $\operatorname{Tr}-9$ Trichophyton sp.enzim üreticisi olarak seçilmiştir.

\section{Enzimin saflaştırılması}

Tr-9 Keratinaz enzimi 3 aşamalı işlemle saflaştırılmıştır. Öncelikle Amonyum sülfat presipitasyonu ile kısmi saflaştırılması gerçekleştirilenörnekler daha sonra diyaliz (Sigma D9777, MWCO > 14000 Da) işlemine tabii tutulmuştur. Diyaliz işlemleri sonunda en yüksek enzim aktivitesi \%40’lık amonyum sülfat çöktürmesi ile elde edilen örneklerde görülmüştür. Sonraki saflaştırma basamakları \%40'llkçöktürme örnekleri üzerinden yürütülmüştür. İkincil olarak enzim örnekleri sephadeks G-100 (Sigma) kolonundan ve son olarak ise DEAE-Sepharose CL-6B (Sigma) kolonundan geçirilerek saflaştırma işlemi tamamlanmıştır. Şekil 1'de SDS-Page analizinde 3 nolu hat $\operatorname{Tr}-9$ enziminin tek bant görüntüsü saflaştırma etkinliğini göstermektedir.

\section{Moleküler Ağırlık Tayini ve Zymogram Analizi}

Saflaştırma etkinliği ve moleküler ağırlık analizi $\% 10$ 'luk SDS-PAGE ile gerçekleştirilmiştir. Protein bantları gümüş boyama (Rabilloud, 1999) ile elektroforezden sonra görünür hale getirilmiştir. Yapılan çalışma sonucunda Tr-9 keratinaz enziminin moleküler ağırlığı yaklaşık $34 \mathrm{kDa}$ olarak tespit edilmiştir (Şekil 1). Keratinaz enzimlerinin moleküler ağırlıkları üretildiği organizmalara göre farklılıklar göstermekle beraber genel anlamda 18-200 kDa arasındadır (Nam ve ark., 2002). Genellikle yüksek moleküler ağırlıklı keratinazlar metalloproteaz 
sinıfında bulunurlar ve termofilik karakter gösterirler (Farag ve Hassan, 2004). Ancak, Tr-9 keratinaz enzimi 50 kDa'dan daha düşük,serin tip proteaz olması ve mezofilik özelliği ile genel bir keratinaz profili sergilemektedir. $\mathrm{Bu}$ sonuçlar diğer bir çok araştırmacının Trichophyton sp.den izole ettikleri 30-
$50 \mathrm{kDa}$ arasında Keratinaz enzimleri ile uyum içerisindedir (Day ve ark., 1968; Apodaca ve McKerrow, 1985; Asahi ve ark., 1985; Tsuboi ve ark.,1987; Rojanavanich ve ark., 1990; Qin ve ark.,1992; Moallaei ve ark.,2006; Anbu ve ark., 2008; Cai ve Zheng, 2009).

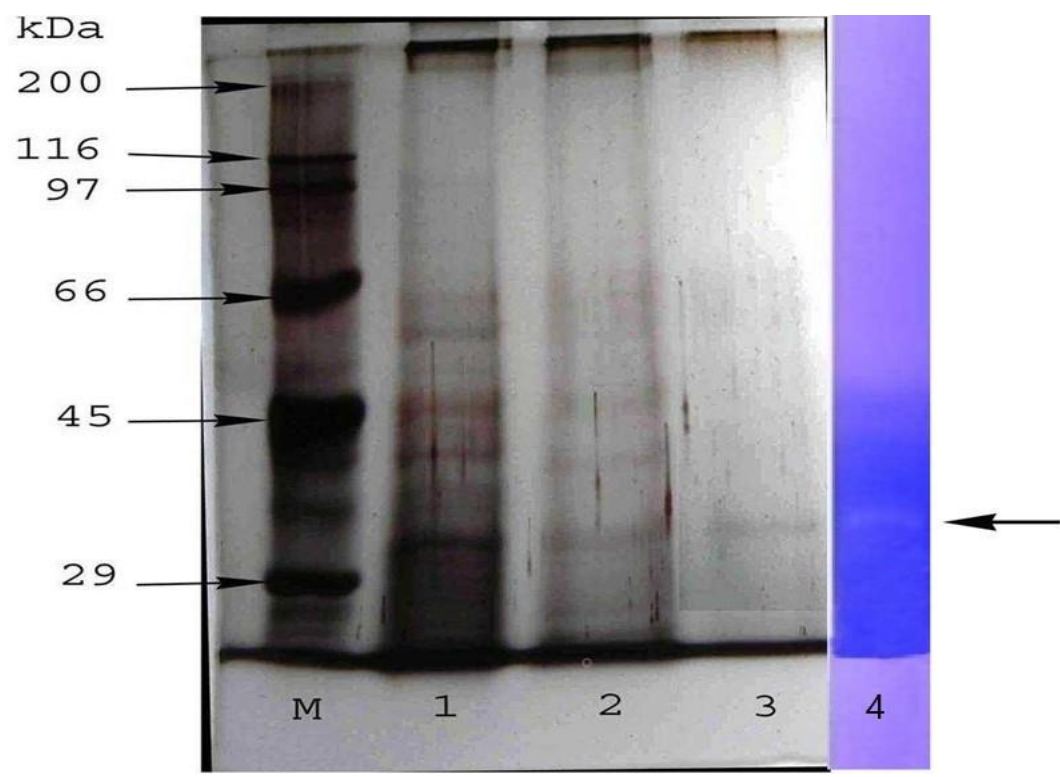

Şekil 1. Tr-9 Keratinaz enziminin gümüş boyama ve zimogram analizi görüntüsü.

Figure 1.Silver staining and zymogram analysis of the keratinase enzyme TR-9.

M)Markör (Sigma,SDS6H2)1)Süpernatant2)Amonyum sülfat presipitasyonunun (\%40’lı grup) ardından Sephadeks G 100 kolon kromotografisinden geçirilen enzim örneği, 3) Amonyum sülfat presipitasyonunun (\%40'llk grup) ardından sirasıyla Sephadeks G 100 kolon kromotografisi ve DEAE sepharose kolon kromotografisinden (0.5 M'lık NaCl eluatı) geçirilen enzim örneği,4)Tr-9 enzim örneğinin zymogram analizi

M) Marker (Sigma,SDS6H2) 1)Süpernatant 2) Enzyme sample subjected to Ammonium sulfate precipitation (40\% )then Sephadex G 100 column 3) Enzyme sample subjected to Ammonium sulfate precipitation (40\%)then Sephadex G 100 column and DEAE sepharose (0.5 M of $\mathrm{NaCl}$ eluat) 4)Zymogram analysis of TR-9 enzyme

\section{Tr-9 Keratinazın Enzimatik Özellikleri}

Tr-9 keratinaz enziminin farklı pH aralıklarında tampon sistemleri kullanılarak belirlenen optimum pH'sının 7.5 olduğu tespit edilmiştir (Şekil 2). Literatüre bakıldığında keratinazların birçoğunun alkali ve nötral $\mathrm{pH}$ aralığında aktif olduğu görülmektedir, nadiren de asidik $\mathrm{pH}$ aralıklarında aktiftirler (Takami ve ark., 1999; Asahi ve ark. 1985 McKerrow ve Apodaca, 1985; Riffel ve ark., 2003; Anbu ve ark., 2008).

Optiumum sicaklık denemelerinde, enzim $20^{\circ} \mathrm{C}$ 'de $\% 52$ rölatif aktivite gösterirken daha sonraki sicaklık değerlerinde kademeli bir artış göstermiş ve $37^{\circ} \mathrm{C}$ 'de ise \%100'e ulaşmıştır (Şekil 3). Keratinaz enzimi ile yapılan diğer optimum sıcaklık çalışmalarında bir çok araştırmacı $40-65{ }^{\circ} \mathrm{C}$ arasında bir değer rapor ederken (Bernal ve ark.,2003; Raju ve ark., 2007; Anbu ve ark., 2008; Moreira ve ark. 2009) Myrothecium verrucaria'dan izole ettikleri enzimin optimum sıcaklığını benzer şekilde $37^{\circ} \mathrm{C}$ olarak saptamışlardır. Tr-9 Keratinaz enziminin insan ve hayvan vücut yüzeylerinde aktif olduğu düşünülecek olursa $37^{\circ} \mathrm{C}$ gibi bir optimum sicaklık değerinin normal olduğu kabul edilebilir.
Enzimin $30 \mathrm{dk}$ ön inkübasyonu sonras $120^{\circ} \mathrm{C}$ de enzimin aktivitesinin \% 70'e yakın korunduğu, $30^{\circ} \mathrm{C}$ 'de \% 65 korunduğu, $40^{\circ} \mathrm{C}$ 'de \% 63 oranında korunduğu $40^{\circ} \mathrm{C}$ 'nin altındaki değerlerde ise enzim aktivitesinin kademeli olarak düştüğü görülmüştür. Sonuçta enzim $20-40^{\circ} \mathrm{C}$ aralığında aktivitesini \% 60 in üzerinde korunduğu tespit edilmiştir (Şekil 4). Anbu ve ark. 2008, ise Trichophyton HA-2 suşundan elde ettikleri ekstraselüler keratinazın $20-45^{\circ} \mathrm{C}$ aralığında stabil olduğunu bildirerek bu çalışmayla hemen hemen aynı sonucu elde etmişlerdir.

Diğer yandan Tr-9 enzimi $\mathrm{pH}$ : 5.5-7.5 aralığında başlangıç aktivitesinin yaklaşık olarak \% 100 oranında koruduğu görülmektedir (Şekil 5).

pH 8.0'den itibaren enzimin aktivitesinde kademeli bir düşüş yaşanmaktadır öyle ki pH: 9.0 'da enzim aktivitesini \%85 oranında kaybettiği görülmektedir. Birçok araştırmacı pH 5.0 ile 12.0 arasında değişen oranlarda stabilite tespit etmişler (Gradisar ve ark. 2005; Anbu ve ark. 2008; Moreira ve ark. 2009) ve Tr9 Keratinaz enzimi de bu bulgular ile uyum içerisinde olduğu görülmüştür. 


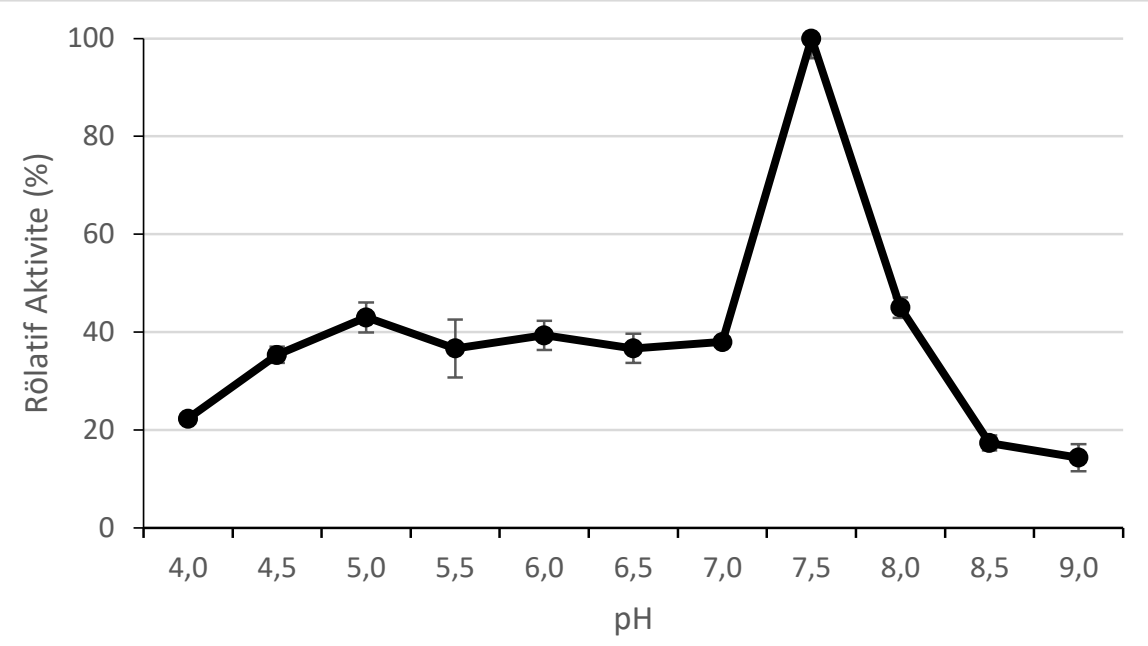

Şekil 2. Tr-9 Keratinaz enzimi üzerine pH'nın etkisi

Figure 2.The effect of $\mathrm{pH}$ on the activity of Tr-9 Keratinase

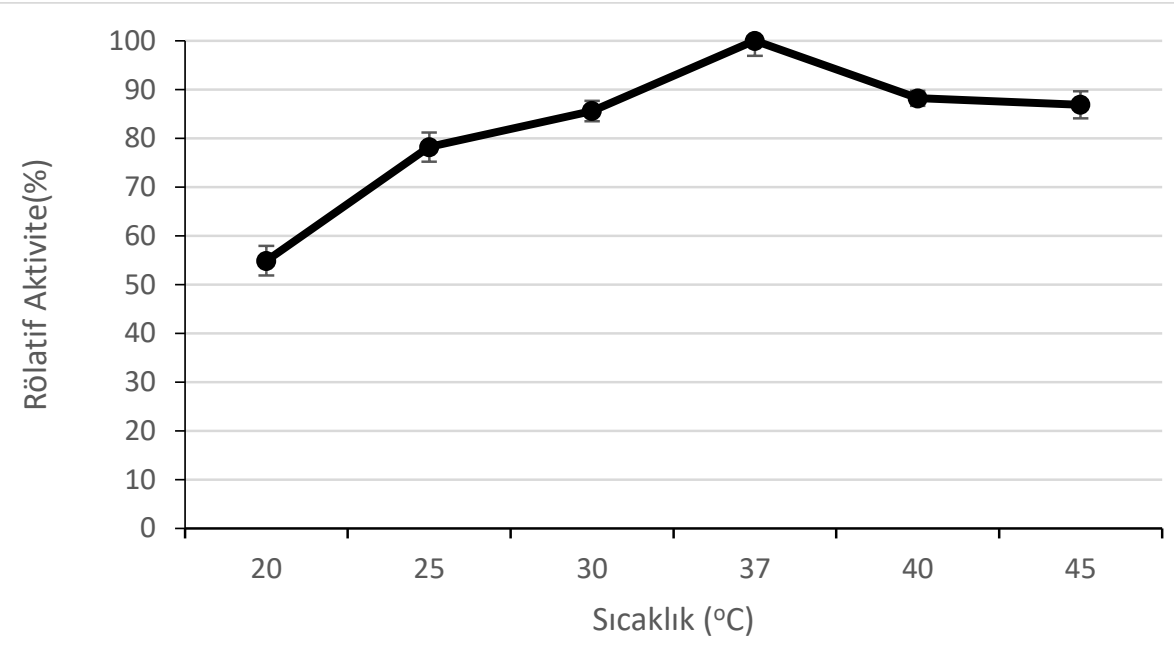

Şekil 3.Sicaklığın Tr-9 keratinaz üzerine etkisi

Figure 3. The effect of temperature on Tr-9 keratinase

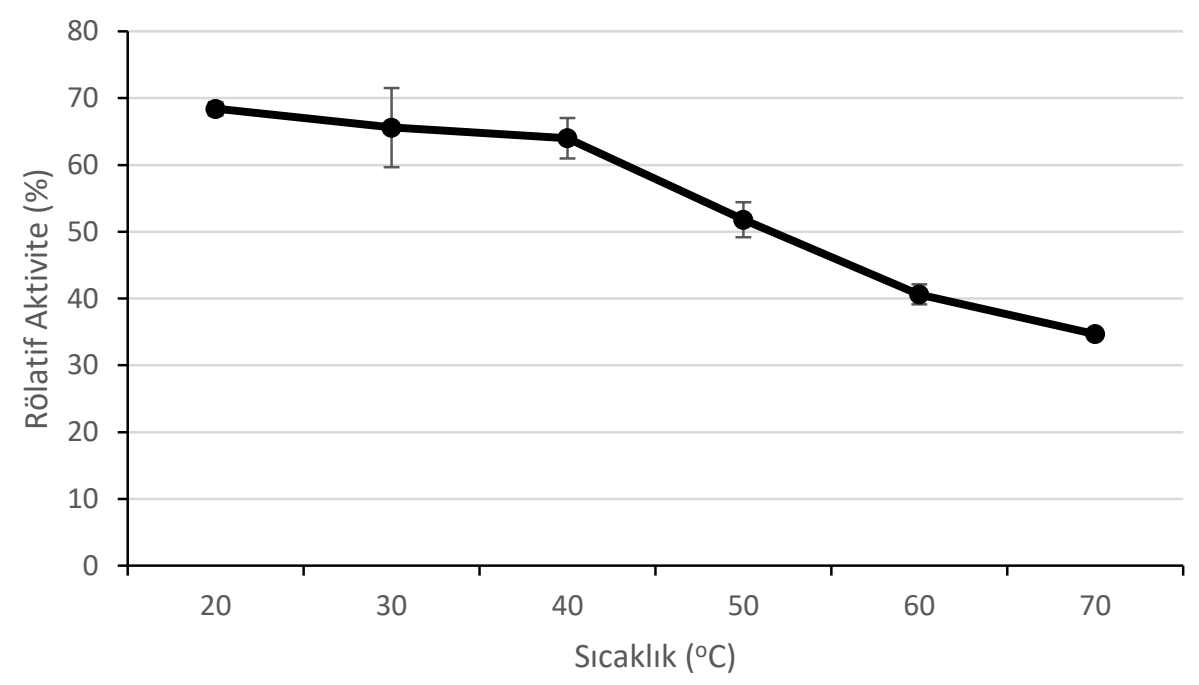

Şekil 4. Tr-9 keratinaz enziminin termal stabilitesi

Figure 4. Thermal stability of Tr-9 keratinase 


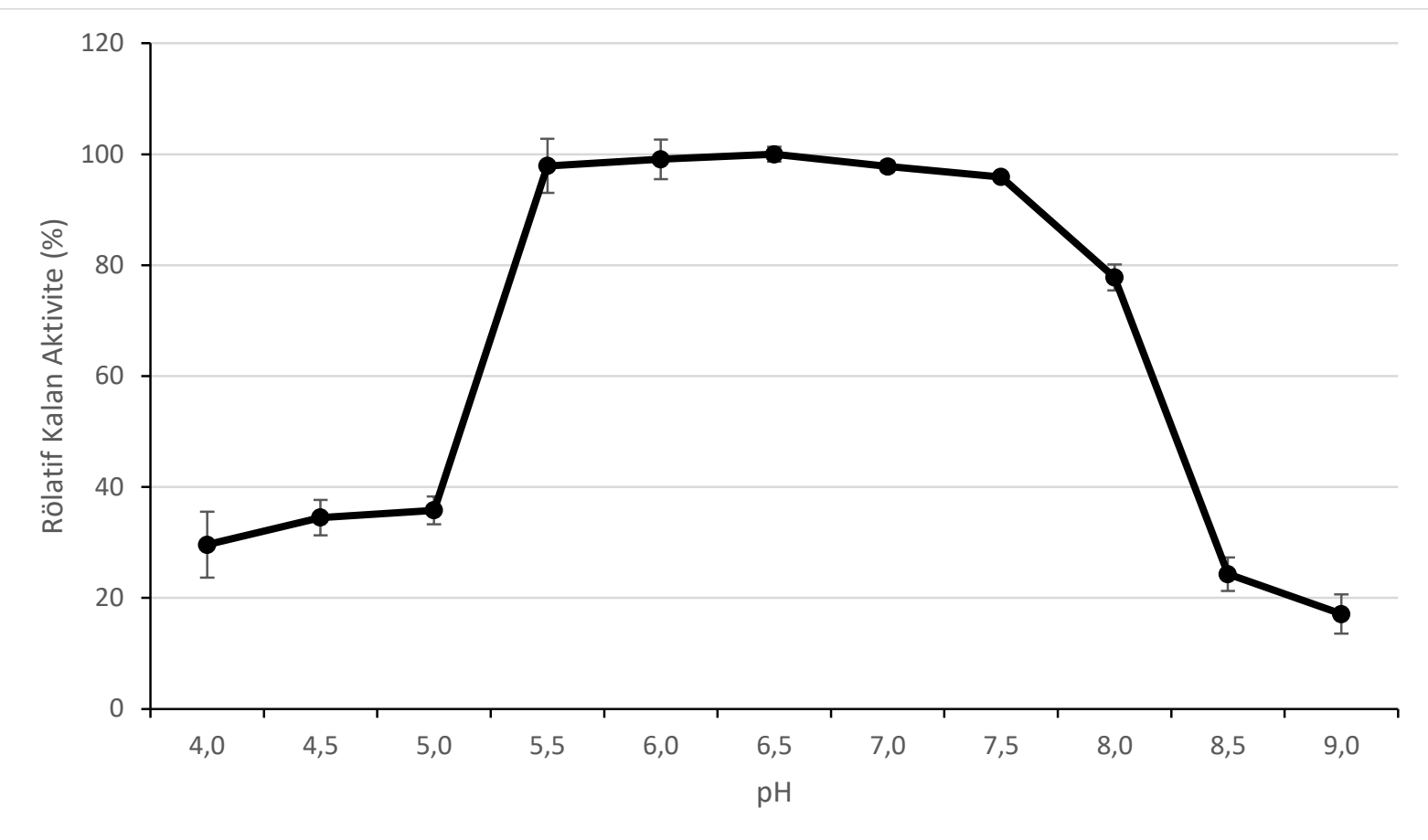

Şekil 5.Tr-9 keratinaz enziminin $\mathrm{pH}$ stabilitesi

Figure 5. Tr-9pH stability of $T^{-}-9$ keratinase

Enzim üzerine farklı kimyasalların etkisi araştırıldığında $\mathrm{FeCl}_{3}$ ve $\mathrm{CaCl}_{2}$ hem $1 \mathrm{mM}$ hem de $5 \mathrm{mM}$ konsantrasyonlarda aktiviteyi arttırdığı, özellikle $\mathrm{CaCl}_{2}$ nin 5mM konsantrasyonda aktiviteyi \% 148 oranında çıkardığı görülmektedir, $\mathrm{ZnCl}_{2}$ 'nin ise $1 \mathrm{mM}$ konsantrasyonda enzim aktivitesini \%56 oraninda azalttığ, $5 \mathrm{mM}$ konsantrasyonda ise aktiviteyi \%66 oranında azalttığı görülmektedir (Şekil 6).

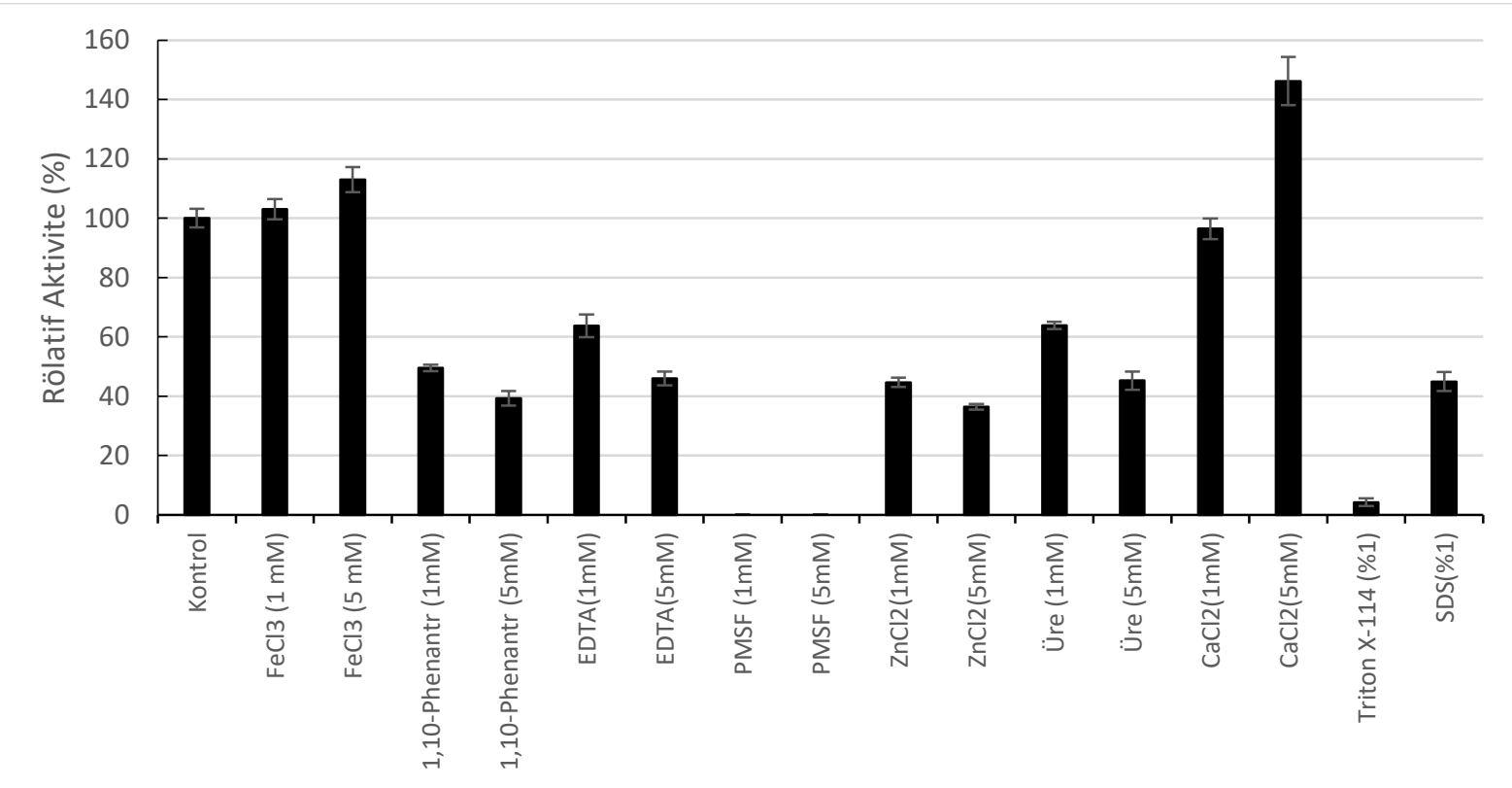

Etken Madde

Şekil 6. Tr-9 Keratinaz enzimi üzerine metal iyonları, inhibitör, deterjanlar ve şelatörlerin etkisi Figure 6. Tr-9 Effect of metal ions, inhibitors, detergents and chelators on Tr-9 keratinase enzyme

Benzer şekilde (Asahi ve ark. 1985) T. rubrum'un ürettiği ekstraselüler proteazın ve (Tsuboi ve ark. 1989) T. mentagrophytes'den elde edilen ekstraselüler proteazla yapılan çalışmalarında da $\mathrm{CaCl}_{2}$ 'nin enzim aktivitesini \%220 arttırdığı bildirilmiştir. Bir noniyonik deterjanlar olan Triton-X 114 'ün \% 1'lik konsantrasyonu \% 98 oranında bir aktivite kaybına sebep olmuştur. SDS (\% 1) ise enzimde \% 51 oranında 
bir inhibisyon gerçekleştirmiş̧tir. PMSF, enzimi tamamen inhibe ederken EDTA ve ürekonsantrasyon arttıkça artan bir inhibisyon gerçekleştirmiştir. PMSF ile güçlü EDTA ile kısmi bir inhibisyon enzimin serin tip proteaz olduğunu göstermektedir (Riffel ve ark., 2003; Moreira ve ark., 2009; Dubey ve ark.,2010). Enzim aynı zamanda bir metallo proteaz inhibitörü olan 1.10-phenantroline ile de kısmen aktivite kaybına uğramıştır. EDTA'nın artan konsantrasyonunda inhibisyonun varlığ aktivasyonun artması enzimin metalik kofaktör ihtiyacını ve enzim stabilizasyonunun arttığını göstermektedir (Habbeche ve ark., 2013).
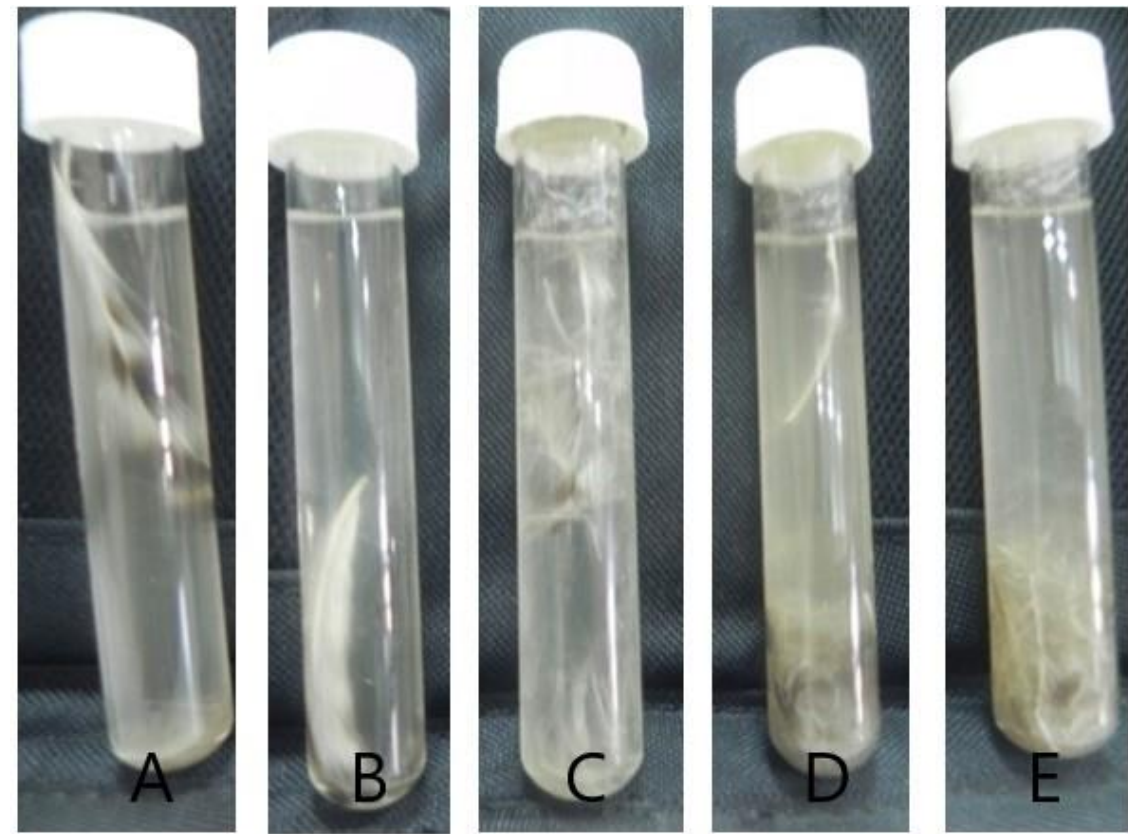

Şekil 7. Tr-9 Keratinaz ile inkübasyona bırakılan tavuk tüyleri

A: 1. Gün B: 2.Gün C:4. Gün D: 6.Gün E: 9.Gün

Figure 7.Chicken feathers treated with $T r-9$ keratinase enzyme

A: Day 1, B: Day 2, C: Day 4, D: Day 6, E: Day 9

Trichophyton sp. keratinazlarının tavuk tüyünü parçalamada oldukça başarılı ve önemli bir rolünün olduğu belirtilmiştir (Okafor ve Ada,2000). Şekil 7 de görüldügü gibi Tr-9 keratinaz enzimi de tavuk tüyleri üzerine aktivasyonu ortaya konmuştur. (Anbu ve ark. 2008; Pandian ve ark.,2012) da yaptıkları çalışmalarda ekstrasellüler keratinazların tavuk tüyleri üzerine etkinliklerini ortaya koymuşlardır.Tavuk eti işletmelerinde üretilen tüy atıkları faydalı protein ve aminoasitlerin üretim potasiyellerini barındırmaktadır. $\mathrm{Bu}$ ise fayvan beslemeciler için ucuz ve alternatif yem katkısı olarak öenm arz etmektedir (Onifade ve ark. 1998).

\section{SONUÇ}

Mikrobiyal keratinazlar, oldukça sert yapıda olan ve güçlü çapraz bağlara sahip, çözünmesi zor olan olan keratini parçalama kabiliyetleriniden ötürü biyoteknolojik olarak önemli yer tutmaktadır. Özellikle hayvan beslenmesinde, derilerin tabaklama işlemlerinde, biyohidrojen üretimindeve bazı tarımsalbiyomedikal uygulamalarda keratinazlardan faydalanılmaktadır (Balint, 2005; Friedrich ve ark,, 2005; Gradisarve ark., 2005; Mohorcic ve ark., 2007).

Mikrobiyal kaynaklar, keratin gibi birçok polimerin biyolojik dönüşümü içinbüyük ölçekli üretimleri açısından önemli endüstriyel aktörlerdir. $\mathrm{Bu}$ çalışmada keratinaz enzimi üretebilen Trichophyton sp. Tr-9 suşundan keratinaz üretimi, saflaştırılması ve kısmi karakterizasyonu gerçekleştirilmiştir. Nötr bir optimum pH'ya sahip olması, pH 5.5 - 7.5 arasinda \%100'e yakın bir pH stabilteye sahip olması, vücut sıcaklığında optimum sıcaklık sergilemesi bir çok endüstriye alanda ve özellikle farmakolojik-kozmetik uygulamalarda potansiyele sahip keratinaz enzimidir.

\section{Teşekkür}

$\mathrm{Bu}$ çalışma KSU Bilimsel araştırmalar birimi tarafindan 2009/4-6M Nolu proje ile desteklenmiştir.

\section{Çıkar çatışması beyanı}

Yazarlar arasında çıkar çatışması yoktur.

\section{Yazar Katkı Oranları}

Yazarlar makaleye eşit oranda katkı sağladıklarını beyan ederler. 


\section{KAYNAKLAR}

Anbu P, Hilda A, Sur HW, Hur BK, Jayanthi S 2008. Extracellular keratinase from Trichophyton sp. HA-2 isolated from feather dumping soil. Int Biodeterior Biodegrad 62:287-292.

Apodaca G, McKerrow, JH 1985. Purification and Characterization of a 27,000- $\mathrm{Mr}$ Extracellular Proteinase from Trichophyton rubrum. Infect. Immun,57(10): 3072-3080.

Arikan B, Unaldi N, Coral G, Colak O, Aygan A, Gulnaz O 2003. Enzymatic properties of a novel thermostable, thermophilic, alkaline and chelator resistant amylase from an alkaliphilic Bacillus sp. isolate ANT-6. Process Biochemistry, 38:1397-1403.

Asahi M, Lindquist R, Fukuyama K, Apodaca G, Epstein W.L, McKerrow JH 1985. Purification and Charaterization of Major Extracellular Proteinases from Trichophyton rubrum. Biochem. J., 232:139144.

Balint B, Bagi Z, Toth A, Rakhelye G, Perei K, Kovacs KL 2005. Utilization of Keratin-Containing Biowaste to Produce Biohydrogen. Applied Microbiology and Biotechnology, 69:404-410.

Bernal C, Vidal L, Valdivieso E, Coello N 2003. Keratinolytic Activity of Kocuria rosea. World J. Microbiol. Biotechnol., 19:255-261.

Bernal C, Cairo J, Coello N 2006. Purification and characterization of a novel exocellular keratinase from Kocuria rosea. Enzyme Microbial Technol 38:49-54.

Bhat MK 2000. Cellulases and Related Enzymes Inbiotechnology. Biotechnology Advances, 18:355383.

Cai, CG, Lou, BG, Zheng XD 2008. Keratinase Production and Keratin Degradation by a Mutant Strain of Bacillus subtilis. Zhejiang Univ. Sci. B, 9:60-67.

Day WC, Toncic P, Stratman SL., Leuman U, Harmon SR 1968. Biochim. Biophys. Acta, 167: 596-606.

Dubey R, Adhikary S, Kumar J, Sinha N 2010. Isolation, Production, Purification, Assay and Characterization of Alkaline Protease Enzyme from Aspergillus niger and Its Compatibility with Commercial Detergents, Developmental Microbiology and Molecular Biology, 1(1):75-94.

Esawy MA 2007. Isolation and Partial Characterization of Extracelluler Keratinase from a Novel Mesophilic Streptomyces albus AZA. Research Journal of Agriculture and Biological Sciences, 3(6):808-817.

Fakhfakh-Zouari N, Hmidet N, Haddar A, Kanoun S, Nasri M 2010. A Novel Serine Metallokeratinase from a Newly Isolated Bacillus pumilus A1 Grown on Chicken Feather Meal: Biochemical and Molecular Characterization. Appl Biochem Biotechnol, 162:329-344.
Farag AM, Hassan MA 2004 Purification, Characterization and İmmobilization of a Keratinase from Aspergillus orizae. Enzyme Microb. Technol., 34:85-93.

Ferrero MA, Castro GR, Abate CM, Baigori MD, Sineriz F1996. Thermostable Alkaline Proteases of Bacillus licheniformis MIR 29: Isolation, Production and Characterization. Appl MicrobiolBiotechnol., 45:327-332.

Friedrich J, Gradisar H, Vrecl M, Pogacnik A 2005. In vitro Degradation of Porcine Skin Epidermis by a Fungal Keratinase of Doratomyces microsporus. Enzyme Microb. Technol., 36:455-460.

Gradisar H, Friedrich J, Krizaji I, Jerala R 2005. Similarities and Specificities of Fungal Keratinolytic Proteases: Comparison of Keratinases of and Doratomyces microsporus to Some Known Proteases. Appl. Environ. Microbiol., 71:3420-3426.

Gupta R, Gupta K, Saxena RK, Khan S 1999. Bleachstable, alkaline protease from Bacillus sp. Biotechnol Letts 21:135-138.

Gupta R, Gigras P, Mohapatra H, Goswami VK, Chauhan B 2003. Microbial a amylases: a Biotechnological Perspective. Process Biochem., 118.

Gousterova A,Braikova D,Goshev I,Christov P,Tishinov K,Vasileva-Tonkova E, Haertlé T, Nedkov P2005,Degradation of keratin and collagen containing wastes by newly isolated thermoactinomycetes or by alkaline hydrolysis Lett Appl Microbiol.40(5):335-40.

Habbeche A, Saoudi B, Jaouadi B, Haberra S, Kerouaz B, Boudelaa M, Badis A,Ladjama A 2014. Purification and biochemical characterization of a detergent-stable keratinase from a newly thermophilic actinomycete Actinomadura keratinilytica strain Cpt29 isolated from poultry compost. J. Biosci. Bioeng. 117:413-421.

Horikoshi K 1999. Alkaliphiles: Some Applications of their Products for Biotechnology. Microbiol. Mol. Bio., 63:735-750.

Korkmaz H, Unaldı MN, Aslan B, Coral G, Arikan B, Dinçer S, Colak O 2003. Keratinolytic activity of Streptomyces strain BA7, a new isolate from Turkey. Ann Microbiol., 53: 85-93.

Kreplak L, Doucet J, Dumas P, Briki F 2004. New Aspects of the $\alpha^{-}$helix to B-Sheet Transition in Stretched Hard a -Keratin Fibers. Biophys. J., 87:640-647.

Langeveld JPM, Wang JJ, Van de Wiel DFM, Shih GC, Garsen J, Bossers A, Shih JCH 2003. Enzymatic Degradation of Prion Protein in Brain Stem from Infected Cattle and Sheep.JID., 188:1782-1789.

Marcondes NR, Taira CL, Vandresen DC, Svidzinski TIE, Kadowaki MK, Peralta RM 2008. New Feather-Degrading Filamentous Fungi. Microb. Ecol., 56:13-17. 
Mckittrick J, Chen PY, Bodde SG, YangW,Novitskaya EE, Meyers MA 2012. The Structure, Functions, and Mechanical Properties of Keratin. JOM, Vol. 64, No. 4.

Moallaei H, Zaini F, Larcher G, Beucher B, Bouchara JP 2006. Partial Purification and Characterization of a $37 \mathrm{kDa}$ Extracellular Proteinase from Trichophyton vanbreuseghemii. Mycopathologia, 161:369-375.

Mohamedin AH 1999. Isolation, Identification and some Cultural Conditions of a Protease Producing Thermophilic Streptomyces strain Grown on Chicken Feathers as a substrate. Int. Biodeterior. Biodegrad., 43:13-21.

Mohorcic M, Torkar A, Friedrich J, Kristl J, Murdan S 2007.An Investigation into Keratinolytic Enzymes to Enhance Ungual Drug Delivery. Int. J. Pharm., 332:196-201.

Moreira-Gasparin FG, Souza CGM, Costa AM, Alexandrino AM, Bracht CK, Boer CG, Peralta RM 2009. Purification and Characterization of an Efficient poultry Feather Degrading-Protease from Myrothecium verrucaria. Biodegradation, 20:727736.

Muhsin TM, Hadi RB 2002. Degradation of Keratin Substrades by Fungi Isolated from Sewage Sludge. Mycopathologia, 154: 185-189.

Nam GW, Lee DW, Lee HS, Lee NJ, Kim B, ChoeEA, Hwang JK, Suhartono, MT, Pyun YR 2002. NativeFeather Degradation by Fervidobacterium islandicum AW-1, a Newly Isolated KeratinaseProducing Thermophilic Anaerobe. Arch. Microbiol., 178:538-547.

Okafor JI, Ada N 2000. Keratinolytic Activity of five Human Isolates of the Dermatophytes. Journal of Common Diseases, 32,300-305.

Onifade AA, Al-Sane NA, Al-Musallam, AA, AlZarban, S 1998. Potentials for Biotechnological Applications of Keratin-Degrading Microorganisms and their Enzymes for Nutritional Improvement of Feathers and Other Keratins as Livestock Feed Resources. Bioresour. Technol., 66:1-11.

Pandian S, Sundaram J, Panchatcharam P 2012. Isolation, Identification and Characterization of Feather Degrading Bacteria. European Journal of Experimental Biology, 2(1):274-282.

Qin LM, Dekio S, Jidoi J 1992. Some Biochemical Characteristics of a Partially Purified Extracellular Keratinase from Trichophyton schoenleinii. Zentralbl Bakteriol., 277:236-244.

Rabilloud T, Blisrick T, Heller M, Luche S, Aebersold R, Lunardi J, Braun-Breton C 1999.Analysis of membrane proteins by two-dimensional electrophoresis: Comparison of the proteins extracted from normal or Plasmodium falciparum infected erythrocyte ghostsElectrophoresis,20, 3603-3610.

Raju K C, Neogi U, Saumya R, Goud N R 2007. Studies on Extracellular Enzyme Keratinase Dermatophyte Microsporum gypseum. International Journal of Biological Chemistry, 1(3): 174-178.

Rao MB, Tanksale AM, Ghatge MS, Deshpande VV 1998. Molecular and Biotechnological Aspects of Microbial Proteases. Microbiol. Mol. Biol. Rev., 62(3):597-635.

Riffel A, Ortolan S, Brandelli A 2003. De-hairing Activity of Extracellular Proteases Produced by Keratinolytic Bacteria. Journal of Chemical Technology \& Biotechnology, 78(8): 855-859.

Riffel A, Brandelli A, Bellato S, de M, Gustavo HMF, Eberlin MN, Tavares FCA 2007. Purification and characterization of a keratinolytic metalloprotease from Chryseobacterium sp. kr6. J Biotechnol 128:693-703.

RojanavanichV,YoshiikeT, Tsuboi R, Takamori K, Ogawa, H 1990. Purification and Characterization of an Extracellular Proteinase from Hendersonula toruloidea. Infect. Immun., 58(9): 2856-2861.

Suntornsuk W, Suntornsuk L 2003. Feather Degradation by Bacillus sp. FK 46 in Submerged Cultivation. Bioresour. Technol., 86:239-243.

Takami H, Nogi Y, Horikoshi K 1999. Reidentification of Keratinase Producing Facultatively Alkaliphilic Bacillus sp. AH-101 as Bacillus halodurans. Extremophiles, 3:293-296.

Tanış H, Cihangir N 2009. Klinik İzolatlardan Elde Edilen Trichophyton rubrum ve Trichophyton mentagrophytesin Proteaz Aktivitelerinin Araştırılması. F.Ü. Sağ.Bil. Tıp Derg., 23(3):137144.

Tsuboi R, Ko IJ, Takamori K, Ogawa H 1989. Isolation of a Keratinolytic Proteinase from Trichophyton mentagrophytes with Enzymatic Activity at Acidic pH. Infect. Immun.,57:3479-3483.

Vidyasagar M, Prakash S, Jayalakshmi SK, Sreeramulu K. 2006. Optimization of cultural conditions for the production of halo thermophilic protea sefrom halophilic bacterium Chromohalobacter sp. TVSP101.World. J Microbiol Biotechnol 23:655-662

Voet D, Voet JG, Pratt CW2008. Fundamentals of Biochemistry: Life at the Molecular Level.3rd. ed. New York: Wiley. 